\title{
"You have reached your destination!" Position, positioning and superpositioning of space through car navigation systems
}

\author{
T. Thielmann \\ SFB/FK 615, Project "Media Geography", University of Siegen, Germany \\ Received: 8 May 2006 - Published in Soc. Geogr. Discuss.: 1 September 2006 \\ Revised: 12 January 2007 - Accepted: 19 April 2007 - Published: 14 June 2007
}

\begin{abstract}
Recent cultural and social theory has paid increasing attention to the category of space. What has received less attention, however, are ideas of navigation through space. Topographic questions started to be debated within the framework of new media as early on as the 1960's, resulting in the interest since this time in localization of information and visualization of informational spaces being inherently connected with map and display media. This paper argues that the convergence in cartographic, media and communication appliances is made particularly clear by the increasing phenomenon of car navigation systems.

The media scientific analysis reveals that the history of car navigation systems is characterized by more commonalities than differences. Invariant constants are the re-discovery of mnemotechnics with Dataland and ETAK Navigator, vertical travel facilities since Aspen Movie Map, step-by-step route guidance since Philips CARIN, 3D navigation, photorealistic representation of urban areas, translucent insert maps, split-screen displays, the superpositioning of the map onto the landscape and in reverse, as well as the constant oscillation between two-dimensional projection space and environmental space, whether with or without a head-up display.

Given this observation of continuity, the fundamental question needs to be posed with reference to a media history of car navigations systems, namely: When do changes in the technical, conceptional and aesthetic properties actually induce differences for media diffusion explanations? This hermeneutic-interpretative analysis is therefore less of an attempt to write a media history of car navigation systems, but more a space concepts overview by and through car navigation systems. ${ }^{1}$
\end{abstract}

\section{Correspondence to: T. Thielmann}

(thielmann@fk615.uni-siegen.de)

${ }^{1}$ A media-ethnographic analysis of car navigation systems that considers Bruno Latour's actor-network theory is in progress (Thielmann, 2007).
This approach reveals that modern car navigation systems are manifestations of media theoretical utopias, in spite of the media evolutionary leveling. With reference to Paul Virilio, it is possible to determine that GPS localization contributes considerably to the normalization of automobile acceleration, which affirms Virilio's science of "dromology". Based on Michel Foucault's spatial understanding, it can be argued that the heterotopia of driving would be perfected with the aid of an "augmented reality" navigation system.

The exposed cross-disciplinary understanding of geography as a cognitive system and more precisely as a superpositioning method, in combination with the fact that trajectography bypasses the prevailing discourses in cartography, and that external data bases or at least entire media systems are incorporated into the map functionality, requires reference to more than just "mobile cartography" or "telecartography". It seems to be appropriate to term media, such as car navigation systems, with converging cartographic and media applications, as the genre of "geomedia".

\section{Starting position}

Whilst commonly comprising elements such as semiotic communications media (images, language, writing, music etc.) and technical transmission media (print, radio, television, internet etc.), media systems are naturally premised on the sensuous perceptive media of space and time (Sandbothe, 2001). Historically, media have always been intertwined with inventions of space. Instead of being an extension of the skin, the use of letters for the phenomenon of human speech already introduced space as an objective reality (De Kerckhove, 2001). Thus this paper focuses on conceptions of space and media, and how we conceive of space as a medium for thought, information and expression.

Published by Copernicus Publications. 


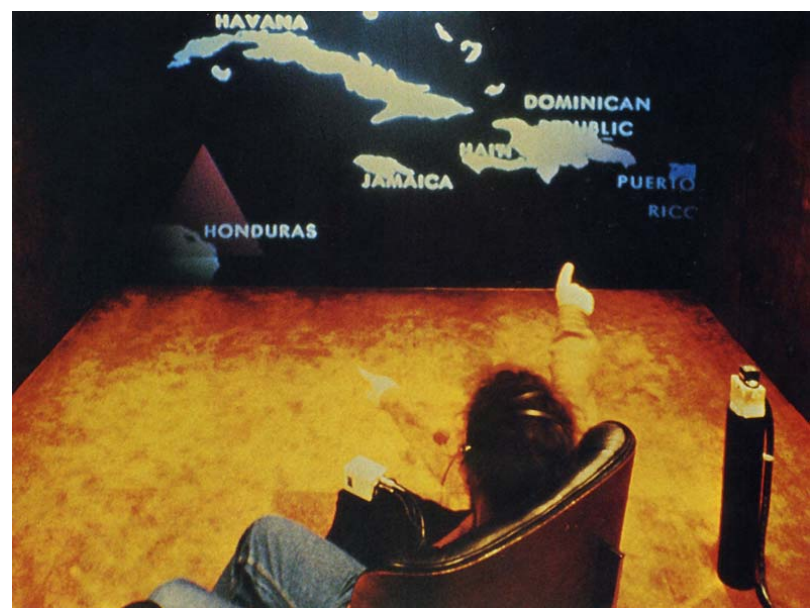

Fig. 1. Media Room: Put-That-There 1979-1980 (Bolt, 1984).

If we operate using an extended concept of the term "media" to include not only technical means of dissemination, but also every type of extension of perception as proposed by Marshall McLuhan (1964), then we can justifiably say that media sciences and social geography do indeed share space as their object of investigation. In order to outline the meaning of space in media sciences, in particular of maps as a representation of space and culturally meaningful "thick texts" (Harley, 1988), we initially need to look back at the history of media.

\section{Location of information}

Computer visualizations emerged during the 1960s with a very much topographical point of interest. The psychologist George A. Miller (1968:286) reacted to the idea of two recording media common at the end of the 1960s with the question: "Where in the world is the information?" One of these media was microfilm, the other the computer. Neither medium revealed the data and information entered into it at first glance, and this in Miller's view is what connected. It was no longer possible to physically locate them. In a sense they have disappeared onto a strip of celluloid and the hard disk or other similar data media.

Even today, microfilm must first be projected so that the user can read the entries of interest, in contrast to the traditional book, for example. Furthermore, in contrast to a library where the location of a book results from the systematic coherent ordering of a spatially distributed stock and therefore remains tangible, the "location" of the entries stored on microfilm or computer were no longer easily accessible or navigable at that time.

"With the new methods of storing information, however, we can no longer go to it and take it in hand directly. The information now is in microform, or binary digits, or is otherwise made physically inaccessible. Since I cannot go into the storage system myself, I must hold a dialog with it on some console whose spatial location relative to the information is completely irrelevant to the system" (ibid. 288).

Data output from the first minicomputers (the $P D P-8$ was first marketed in 1965) was still restricted to printouts (Ceruzzi, 2003). Although the TX-0 mainframe computer, developed in 1955, already had a cathode-ray tube display and $D E C$ 's $P D P-1$ was also sold with a CRT monitor in 1959 , screens for optical data display were not a market success in the 1960s.

\section{Informational space}

In his perceptive article "The Ultimate Display", Ivan Sutherland (1965) proposed his vision of an information environment as a space behind display screens that can be navigated through and "stepped into" via corresponding peripheral appliances, such as the "head-mounted three-dimensional display" (also his invention at the Massachusetts Institute of Technology).

"The ultimate display would, of course, be a room within which the computer can control the existence of matter. A chair displayed in such a room would be good enough to sit in. Handcuffs displayed in such a room would be confining, and a bullet displayed in such a room would be fatal. With appropriate programming such a display could literally be the Wonderland into which Alice walked" (Sutherland, 1965:508). At a later stage, this space was to be called "virtual reality". Sutherland thereby also preempted the spatial metaphor of "cyberspace", that has now become firmly established in the arena of information visualization.

The vision of an "ultimate display" was therefore initially a virtual space and not the planar display as we know it today. The Media Room at MIT's Architecture Machine Group laboratory was the setting where the room itself was the terminal for one of the first computer-supported spatial data-management systems, called Dataland, developed under the project leadership of Nicholas Negroponte and Richard A. Bolt (see Fig. 1). ${ }^{2}$ One of the intellectual mentors of the Media Room was Ivan E. Sutherland, apparently due to his vision of space as a medium for information.

This demonstrates that the organization and visualization of information is carried out against the background of a three-dimensional information environment, but perhaps more importantly, visualization of the spatial data-management system was based on the example of a map, itself also entitled an "informational landscape" (Bolt, 1979:13). The map metaphor was chosen with much thought,

\footnotetext{
${ }^{2}$ See the 1981 video of Put-That-There in the supplemental file http://www.soc-geogr.net/2/63/2007/sg-2-63-2007-supplement. zip. More demos are available under the link: www.media.mit.edu/ speech/sig_videos.html (download: 06-11-2007).
} 
given the references to cognitive maps (Tolman, 1948) and findings on the multisensory development of such maps (Neisser, 1976) in the conceptual description of Dataland (Bolt, 1977). The procedures in the computer appeared similar to cognitive processes.

The concrete implementation of the data-management system resulted not only in the visualization of information, but also in its spatial configuration: "Dataland is not a map of data. It $i$ s the data. The nature of the display is 'out there', visually self-evident" (Bolt, 1984:12). Information was allocated to a specific position in space, such that the user was in a position to simultaneously form a cognitive map of the data with the aid of a projected topographic map, helping him in navigating about the Dataland surface and in finding the deposited information. Thus the Media Room came up with an idea that follows on from Miller's question: where in the world the information is. ${ }^{3}$

To develop a framework for the ordering of information, it is no coincidence that a map was chosen as the content of the presumably first virtual space, a space that Bolt (1977: 2) also defines as the space " 'beyond' and 'behind' the physical apparati”, just as Sutherland had declared 12 years previously. From a media scientific viewpoint, maps therefore play a central role in the very early stages of the creation of spatial information systems. Moreover, the relevance of maps has been re-discovered in recent years through computer visualization and dynamization of cartographic imagery, even though cartography must be regarded as the most ancient image science (Pápay, 2005). ${ }^{4}$ One of the best examples of this are mobile navigation systems, such as are employed in vehicles.

The advent of digital technology has led to the establishment within cartography of "mobile cartography" (Reichenbacher and Meng, 2003) or "telecartography"5 as a new topic for research. Of course maps have been mobile for hundreds of years in the sense that it has been possible

\footnotetext{
${ }^{3}$ It can be demonstrated that the question as to the "where", i.e. the "location" of the information, was itself guided by a re-discovery of mnemotechnic by cognitive psychology (see Matussek, 2000). The mnemonic technology or "art of memorizing", that was presumably used for the first time by the Architecture Machine Group in computer technology and here for the organization of memory and representation of information, has since experienced a reception that can hardly be overlooked any longer.

${ }^{4}$ However, this is controversial, as maps are often excluded from the definition of the image concept. For example, Scholz (2004) fundamentally questions whether maps can even be included in the image concept.

5 Gartner understands telecartography to mean "the exchange and transmitting of spatially related information through cartographic products [...], that are accessed through mobile interrogation and distribution appliances and transmitted through media technology" (Gartner, 2000:22).
}

to transport them. ${ }^{6}$ Indeed the novel element is therefore not the mobility of the (digital) map, but crucially the capacity to adapt to its mobile use. This adaptability forms the core of mobile cartography.

Due to the increased saturation in the mobile communications market, dynamic determination of location has become a "killer application" in mobile communication end appliances such as mobile telephones, PDAs etc. Car navigation systems can be regarded as a precursor to this development, as they have established themselves in the market through mass use. ${ }^{7}$ Future developments that result from convergence in navigation and communication technology can be predicted based on the increasing number of on-board and portable car navigation systems. One of the most important further developments by Dataland was also a navigational application, the Aspen Movie Map.

\section{Car navigation and (super)positioning systems}

"The 1978 project Aspen Movie Map, designed at the MIT Architecture Machine Group, headed by Nicholas Negroponte (which later expanded into MIT Media Laboratory) is acknowledged as the first publicly shown interactive virtual navigable space" (Manovich, 2001:259) and, furthermore, the first interactive digital car travel guide (Naimark, 2006). ${ }^{8}$ This program allowed the user to "drive" by videodisk about the streets of Aspen in the US state of Colorado and to choose new directions at each crossroad touching left/right arrows graphically overlaid on a touch-sensitive screen (see Fig. 2). It was also possible to stop, view houses, meet people, or even to change the season (Brand, 1988). The Aspen Movie Map offered a virtual travel through pre-recorded spaces.

Realization of the Movie Map was accomplished by driving through the town of Aspen in the US state of Colorado and taking one frame per every 10 feet of travel by

\footnotetext{
${ }^{6}$ On the mobility of maps, see Scharlach and Müller, 2002.

${ }^{7}$ According to a study by "Strategy Analytics", 7.6 million in-car, 3.3 million portable and 1.6 million mobile telephone navigation systems were sold in 2005 in Europe, Japan and North America. For 2010, a turnover of 11.5 million in-car, 11.1 million portable and 24.9 million mobile telephone navigation systems is expected (TeleTraffic, 2006:21).

${ }^{8}$ See the 1981 video of the Aspen Movie Map in the supplemental file http://www.soc-geogr.net/2/63/2007/ sg-2-63-2007-supplement.zip. The demo is available under the link: www.media.mit.edu/speech/sig_videos.html (download: 06-11-2007). Even though the Aspen Movie Map was created as a simulator, the navigation of which imitated a real car drive, it was not intended as a prototype for car navigation systems. The project was rather more a by-product of the interest in an airport setup true to the original, in which the Israelis had practised freeing the Entebbe airplane hostages in 1973. The Pentagon had asked whether it was possible to simulate such "experimental mapping" on a computer (Brand, 1988:141).
} 


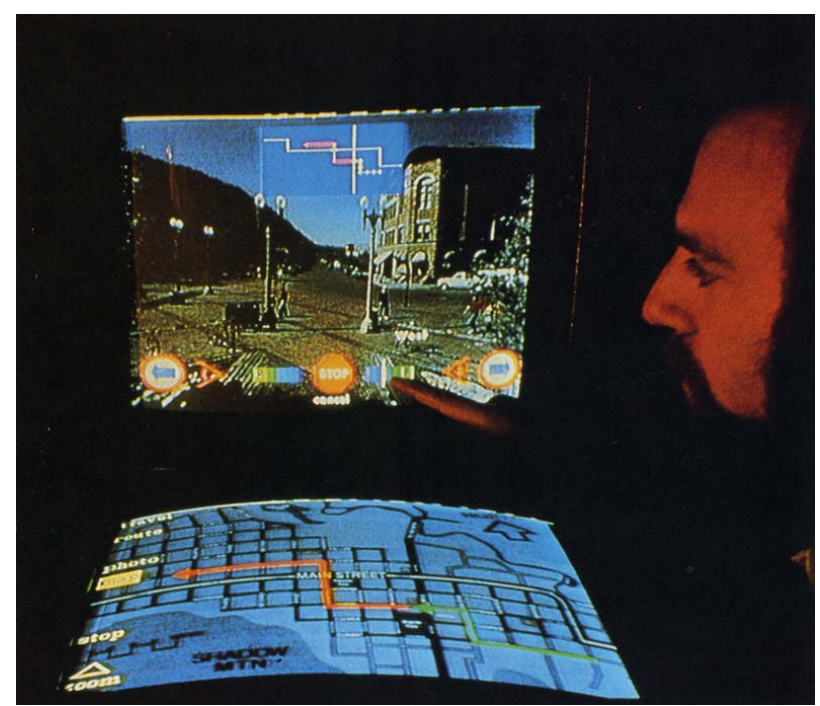

Fig. 2. Aspen Movie Map 1978-1983 (Bolt, 1984).

a set of truck-mounted 16mm stop-frame cameras (Naimark, 1997). This footage was then stored on videodisk. Based on the information provided by a playback system of several laserdisc players, a computer, and a touch-screen display, the corresponding photo series appeared on a color TV monitor. A second horizontally-mounted monitor indicated the current position and direction taken with an arrow on an electronic topographical map, while the track of the route changed from red to green as you "traveled". 9

This corresponds, in essence, to the type of representation we are used to in current navigation systems. The tiny translucent insert map at the top-middle of the video screen is also very similar to the head-up display that superimposes navigational information on a driver's field of view - for example, presently offered for $B M W 5$ and 6 series. ${ }^{10}$ In addition, the user can zoom in on any street intersection of Aspen by switching between an aerial photo, a street map or a detail map view - very much like you can do it with Google Maps and Google Earth today. ${ }^{11}$

Thus, the idea of developing a virtual space on a large scale based on real space and with the aid of photos

\footnotetext{
${ }^{9}$ The first version of the Aspen Movie Map used only one screen (Lippman, 1980).

10 The image produced by a head-up display is reflected onto the windscreen. Just like when looking in the mirror, the driver does not see the image on the surface of the windshield, but floating freely over the hood, at a distance of approximately two meters. To get an idea of the actually available head-up display, see also the broadcast report New Technology to Prevent Driver Distraction (http://www.soc-geogr.net/2/63/2007/ sg-2-63-2007-supplement.zip) produced by Siemens in 2003.

${ }^{11}$ The use of "animated images to provide intermediate vertical travel between a set of aerial photographs and the street" was also intended (Lippman, 1980:39).
}

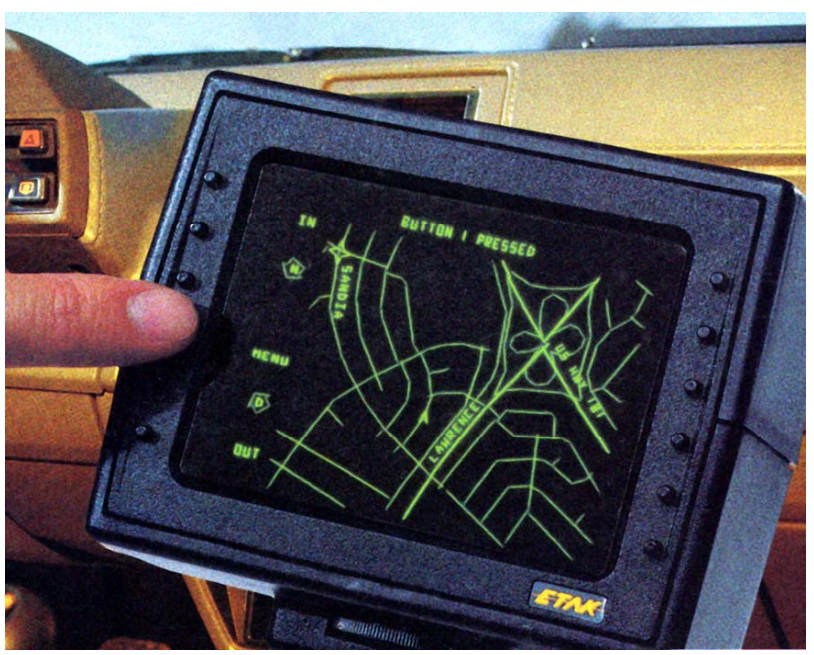

Fig. 3. ETAK Navigator 1985.

and video recordings, was initially not further pursued in those serious vehicle navigation appliances sold since 1985. ${ }^{12}$ For example, the ETAK Navigator, "the first commercially available automobile navigation system based on map matching technology" (French, 1986:355), used representation procedures that had been tried and tested in cartography (see Fig. 3). The complete system with a green vector display (costing 1395 US dollars) was initially only configured for the road network in San Francisco and Los Angeles - the first areas with available map data. ${ }^{13}$

It must be mentioned that vehicle positioning at the time was not yet provided by satellites, but by dead reckoning. In this system the driver starting a journey entered his destination and present position by giving the nearest cross-streets. The measurements from wheel and compass sensors were then combined to determine a sequence of positions which in turn was compared to a map database.

Philips' Car Information and Navigation System (CARIN) also estimated the vehicle's position by advancing a known position using course, speed, time and distance to be traveled. This test prototype was demonstrated shortly after the ETAK Navigator. It represented an important step in the evolution of route visualization technology. While the user

12 The commercial production of car navigation systems began in August 1981, when Honda introduced its Electro Gyro-Cator (Honda, n.d.:6). Other autonomous navigation systems (by Nissan and Toyota) also started appearing in Japan in the early 1980s, but they were not a success. Their accuracy and practicability was low (Mark et al., 1987:216; Parviainen et al., 1988).

13 The ETAK Navigator was invented by Stanley K. Honey. "He knew from his studies of navigation history that the Polynesians navigate vast distances of the Pacific without instruments. By thinking of their canoes as stationary and the island around them as moving, they measure their traveling distance by the 'movement' of the islands. They call this system etak" (Shuldiner, 1985:65). 


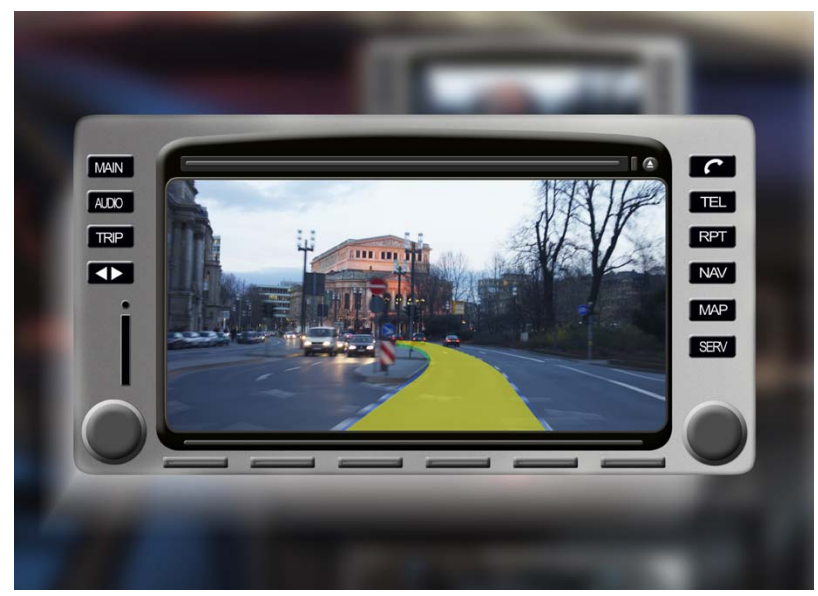

Fig. 4. Navigation system of the "augmented reality" from Siemens-VDO 2002.

of the ETAK Navigator must do their own route planning, the Philips system includes a route-search algorithm and provides step-by-step route guidance (Fernhout, 1987:142; Parviainen et al., 1988:29f.). It is therefore noteworthy that in the Philips CARIN textual and linguistic communication (the system included synthetic speech), as well as graphical and pictogrammatic forms of expression (symbols for petrol station, hotel, restaurant etc.) already function together here, in the way we are familiar with for modern car navigation systems (Crisp, 1985).

This fusion and interaction of different sign systems is not a phenomenon that is restricted to this example, as is clear if we refer to the history of cartography (e.g. Warnke, 1998). However, the increased potential of map distribution and usage only opened up once computer and satellite technology had been connected with telecommunications infrastructure, and through the adaptability of map presentation to factors pertaining to the map user's location, time and situation (Gartner, 2000; Heidmann and Hermann, 2003).

This new subject matter for social geographic research may itself, however, have become superseded by more recent developments. Future location representations will probably operate with greatly reduced symbolic sign systems. For example, the Siemens-VDO navigation systems (see Fig. 4) that have recently been developed dispense with traditional map illustrations, uniform speech commands, as well as abstract arrows and pictograms, since these may distract and confuse the driver, particularly in complex traffic situations (Wagner, 2005). Instead, we are once again approaching the vision put forward by Aspen Movie Map.

The next generation of navigation systems will no longer simply direct the car driver through traffic using arrows, but will represent the environment true to reality. This will be accomplished with a camera that is built into the car and that records the surroundings ahead. An on-board computer

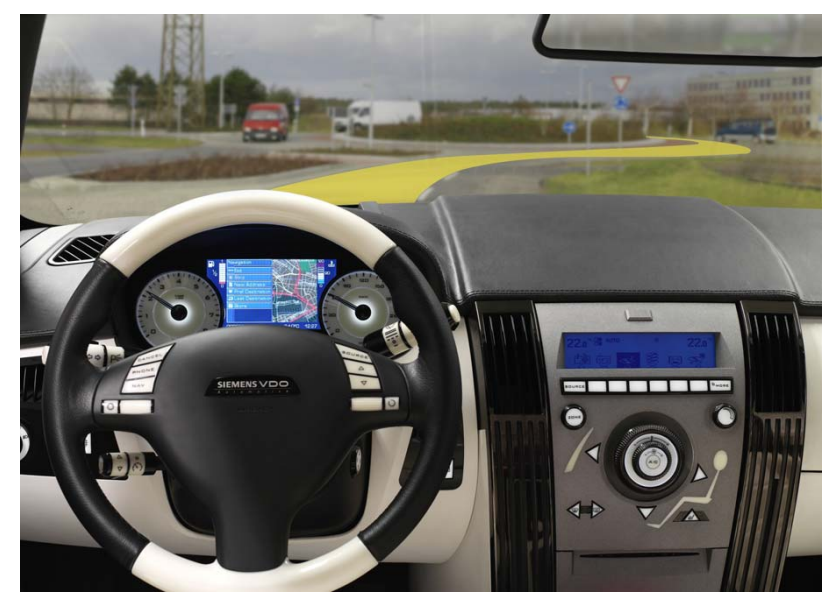

Fig. 5. AR navigation system with head-up display from Siemens-VDO 2005.

will compare the recorded video images with stored street information and incorporate instructions on direction - in the form of three-dimensional arrows for example - into the camera-produced pictures of the surrounding area.

This process, called "augmented reality"14 (AR), gives the driver the same view of the world on the navigation display as they have when looking at the road. The "conversion" of the abstract map image is no longer necessary. In addition, "augmented reality" in combination with a head-up display can ensure that drivers are looking straight at their route (see Fig. 5). Projection onto the windscreen of an integrated video image containing route information will be available for serial installation as early on as 2010 (Wagner, 2005). The constitutional moment of this medium is in fact the constant oscillation between environmental space and two-dimensional projection space. Using the words of Walter Benjamin (1980:18), one could also speak of a transparent translation of the world that should not obscure the original. ${ }^{15}$

On the other hand, a navigation system of this type in combination with a head-up display has the advantage that information which is irrelevant to travel can be masked in its entirety according to the driver's wishes, leaving only pre-defined "points of interest" 16 visible to the driver. From the car, the world could therefore be perceived only as a map.

This kind of superpositioning of the map onto the landscape is an extrapolation of one of the first car navigation

\footnotetext{
${ }^{14}$ In information technology, "augmented reality" represents the possibility of illustrating real and virtual images together.

15 On the spatial quality of language and the emplacement as a process in translation, see Görling (2004:55f).

16 Such "points of interest" can be tourist attractions. The standard routing in pedestrian navigation systems is the guidance from "point of interest" to "point of interest" along a predetermined tour (Pammer and Radoczky, 2002:120).
} 


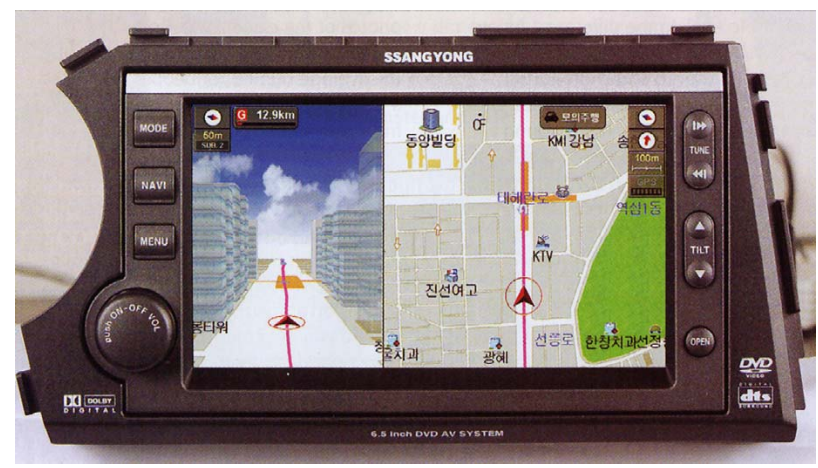

Fig. 6. Ssang Yong's 3-D navigation system (Donohoe and Leroux, 2005:49).

systems, the ETAK Navigator. The ETAK Navigator's route visualization was adapted by Carolinian (Puluwatan) navigators who imagine their canoes to be stationary under the stars while a reference island (or etak) moves. They superimpose temporal landmarks on an inverted image of the movement of the etak island as a model of the voyage.

The key to the ETAK Navigator was that of visualization through Gestalt transition. The user's position remains static in the center of the display, while the map moves underneath the car. This creates the impression of: "it isn't me approaching the destination, rather it is approaching me" (Sommer, 2002:383, own translation). This "mobile egocentricism", pointed out in detail in Manfred Sommer's phenomenological analysis of automobile navigation, has become a universal principle for all car navigation systems since ETAK Navigator.

"By blending all of these into a single image, the navigator constructs an analog computer. This system involves the opportunistic use of material structure as an anchor for the superposition of structure from several input spaces. The model is 'run' by imagining the superposition of several kinds of structure, thereby producing a blended space in which the ability to infer location from time is an emergent property" (Hutchins, 2005:1568). On this level, the Carolinian's navigational knowledge is a body of accretions acting as a "map" of the environment, functioning as a connection between navigational knowledge and physical space.

In cars of the future, the virtual and real worlds move ever closer to each other. This is also demonstrated by the three-dimensional navigation systems that are rapidly expanding in Japan (see Fig. 6), which refer to interactive 3-D computer graphics for their construction of space and deliver entire animations of road features, buildings and road works. "When you sit in the front seat of one of these vehicles, it's like looking at a Playstation 2 game", says Bill Fleck, business development manager at Freescale Semiconductor (Murray, 2004). This is not least due to the fact that Asiatic developers are using technology from the games' industry - the graphics processors for these navigation systems are from games' consoles.

Siemens-VDO Automotive (2005) is also developing a three-dimensional map representation for Europe to further facilitate (dis-)orientation for the car driver. This is based on a so-called "Digital Terrain Model", in which digitized satellite or aerial photographs are laid over a grid of the earth's surface in order to create a photorealistic representation of urban scenarios (see Fig. 9).

To enhance orientation in "the 100 most important cities", numerous famous buildings were not only digitalized, but also constructed by the computer based on floor plans. "As a result, the monitor displays true-to-life images of entire streets that the driver can view from any desired perspective without distortion as if zooming with a video camera" (Siemens VDO Automotive, 2005). This is noteworthy since it suggests that picture distortion is an important problem for navigation that can only be solved with "virtual reality". The final production of this series is expected from the end of 2007.

Even though over 20 years ago Paul Virilio described how vehicles as perceptual machines were ideal candidates for artificial realities in many of their aspects, he most certainly would never have dreamt of such a vision. In view of this development, Virilio's thesis that the modern world had lost an origin of its spatial and temporal living conditions through the (vehicular) acceleration of transmission, does not seem quite so simplistic, as alleged, among others, by Harvey (1989).

\section{Accelerated positioning/Positioning through acceleration}

In spite of all the criticism of Virilio's conjectures shaped by the rhetoric of loss, "it is thanks to his seismographic feeling for invisible figurations within the visible, that his view has led to the revealing of construction rules in technical media other than those of their simple functional evidence", as Tholen (2002:103) quite rightly notes. Virilio's telematic media perception is enlightening in the sense that it can be applied well to navigation systems.

Virilio already noted that the passenger fixed in the car seat is offered a double view that increases the perceptual effect of their vectorial velocity - the puncture of space. Virilio's language stylizes this into the art of the dashboard (Virilio, 1998:12). The driver is fixed between the dashboard and the "screen" presented by the windshield, on which a reality that has become unreal in the real sense of the word is taking place like a film. The proximity of the video game to driving is obvious. While the landscape disappears of its own accord on the velocity vector, the function of the driver is concentrated purely on maintaining the vector and avoiding obstacles. 
Virilio demonstrates this approach in Open Sky (1997), using the car windscreen as a paradigm for a cinema screen that is interpreted as an artificial projection of car and driver. The apocalyptic vision of "the aesthetics of disappearance" is closely linked to this aesthetic core zone. Humans and landscape disappear more and more from the digital semiotic scene, as velocity becomes an end in itself that is devoid of meaning. This poststructuralist absence is to Virilio an absence of the human being who is lost in the "non-location" of velocity.

Two vectors or movements form the axis of abscissas, in the net of which the configurations of the velocity factory are apparent: acceleration and normalization. Virilio calls their genealogy, "dromology"17. According to this, the car's success is the normalization of acceleration, the normality of speed is outside human perception and control. The homely sphere of the inner space in cars is one factor that contributes substantially to this. The driver feels safe in the comfort of the seats and surrounded by security systems, control panels, mirrors and windscreen. High speeds can become normal in this secure space. The dynamic localization also contributes considerably to the normalization of acceleration, in that the navigation display indicates a correct functioning of technology through the constant approaching of the destination. ${ }^{18}$

Means of transport are disorienting. Navigation systems can counteract the "disappearance of detail in the world through the shimmer of speed" (Virilio, 1992:52, own translation), whereby, paradoxically, their orientation performance would not even be possible without movement. In the age of digital technology, movement is an essential prerequisite to orientation in space. This is because, in contrast to analogue maps, the route-dependent orientation of the digital maps can only occur when the navigation system or its user has moved through space (Pammer and Radoczky, 2002:123).

The Global Positioning System (GPS) cannot determine an exact position in the absence of movement. In other words, only movement increases the visual acuity of navigation systems. Indeed this is a rather generic yet important statement: The act of movement that requires more information to be carried out successfully, produces even more information for the moving perceiving subject. More

\footnotetext{
${ }^{17}$ Dromology is derived from the Greek "dromos": avenue or race course. "It therefore deals with the logic of the course. With this, I stepped into a world in which speed and not wealth was the gauge" (Virilio and Lothringer, 1984:45, own translation). In Virilio, dromology appears to be reflected consciousness of a perception, that interprets the world and reality as a resultant of the velocity.

${ }^{18}$ A similar psychologically motivated aim is pursued by Global Positioning Systems, based on which air passengers can follow the current flight position from within the interior of the airplane (Schmaucks, 2001:309).
}

generally humanity was only able to form spatial concepts through movement (Wunderlich, 1985).

While the user of an analogue map automatically orients the representation of the roads on the map in the direction of the road on which they are located, no solution has yet been found for spatial orientation in digital mobile cartography (Lopau, 2003). Traditional maps therefore have a substantial advantage. They provide much better orientation in the mental representation of the spatial environment. In this process, the cognitive system "as it were, overlays the real road with the representation of the road on the map" (ibid. 65). As such, the "augmented reality" navigation system no longer differs from that of cognitive mapping in this particular point ${ }^{19}$.

\section{Theoretical positioning}

In digital operations, space is merely a metaphor. Space exists in the physical world, while a map is only a model of space, not space per se. This model is not spatial, but logistical and therefore also an-aesthetic - not for the physical experience, but for cognition, for our mental computing. The spatial structure of cyberspace is determined purely by topological arrangements. ${ }^{20}$

Even if the meta-idea of a navigation system is to have one's own traversing of space transferred in real-time from the perspective of a satellite into the vehicle in high resolution (i.e. self-observation as orientation in kinetic space), in this particular case, awareness of the mathematical abstract space is high: After all, the digitized and reduced imagery of current navigation systems is based explicitly on vectorial mathematical functions.

19 The term "cognitive mapping" used in cognitive psychology refers to the process of perception of spatial orders in human consciousness. Cognitive maps reflect the world in the way a human thinks it is, without any pretence to correctness. The perspective of the observer is responsible for any aberrations (Downs and Stea, 1982:24).

20 The artificial word "cyberspace", used by William Gibson (1984) in his novel Neuromancer, stands for "cybernetic space" and does not really describe a space, but rather cybernetics as an applied theory for the control of complex systems. The ancient Greek "kybernetes" (governor) does not steer his vehicle on solid ground, but on a liquid element. The navigation metaphor itself implies the sea, that defies cartography. In this sense, the terminology is already geared towards digital navigation systems taking over from static traditional maps and for the static state to be replaced by dynamics. Most cyberspace interfaces or computer games attempt to remove the difference between isotropic space, that is logical mathematically and follows Cartesian rules, and the anthropological, relative notions for space. Even today, there remains a wrongly understood cyberspace term as a spatial medium in which the body could be left behind as it is restricting and an obstruction (see Hipfl, 2004:25). 
This contrasts with the rather more intermittently experienced space that passes by the driver on the other side of the windscreen. This space is perceived as an environment that can be driven through. The environmental space mediated by navigation systems is astoundingly similar to the perception of an environment contorted by speed - "the flowers by the wayside are no longer flowers, but spots or even red and white lines, no dots, only lines" (Virilio, 1992:49, own translation). The internal representation as an internalized perceptual space, however, does differ substantially from the space passing by that is perceived by the navigating car driver as a sequence of distinct points (motorway exits, crossroads etc.).

This process of positioning is highly integrated into a discursive system of spatial description, namely cartography itself. It is the historic bird's-eye view provided by maps that overlays the purely subject-bound orientation through processing of environmental stimuli, even without head-up display, and even in $21 / 2$-D navigation systems with so-called "bird's-eye view". It is knowledge based on the conventions of cartographic symbols and the use of maps that co-determine the moment of positioning and form the conceptualization of an inter-subjective space from the perception of environmental space.

The subject is sitting in the car, where they can also perceive themselves on the map. However, they do not only perceive a map, but an ambivalent fusion of two representations of the landscape: the "projection" onto the windscreen and the projection of the map itself. The description of the drive in the car can be made even more pointed by describing the constellation car-driver as a heterotopia (contre-emplacement). ${ }^{21}$ If we view the emplacements on the other side of the windscreen as a projection onto this screen that the driver sees when sitting still, then the navigation system, the location of the driving cabin, even the entire car in the spatial network of positional relationships, become distant in the accelerated landscape.

The medium becomes prominent and connects two orders in the same space, namely those of the virtual and the real. Space becomes heterogeneous. A barrier is created between different orders, the categorical separation of which can no longer be maintained. Foucault (1986:24) says: "Places of this kind are outside of all places, even though it may be possible to indicate their location in reality." 22 They do not exist for the order of reality, but can still be located as part of this space, as they are real in both their virtual, as well as in the materialization of the media.

\footnotetext{
${ }^{21}$ Heterotopic spaces enable multiple functions. The driver feels at home in the closed interior of a car, while at the same time he himself is nowhere or going somewhere (see Foucault, 1986:22ff.).

${ }^{22}$ The original states "des sortes de lieux qui sont hors de tous les lieux, bien que pourtant ils soient effectivement localisables" (Foucault, 1994:755f.).
}

If one creates a different space when driving, "another real space, as perfect, as meticulous, as well arranged as ours is messy, ill constructed, and jumbled" (Foucault, 1986:27), then the constellation car-driver would have to be allocated to the class of "heterotopias of compensation" proposed by Foucault. The linearity, the well-organized passing by of the world contrasts with the jumbled space of the pedestrian. In this sense, the heterotopia of driving would be perfected with the aid of a navigation system.

In accordance with Edward Soja (1999), the new generation of navigation systems that project the travel route onto the windscreen can also be described as the rise of the perspective of a third space. The driver is himself in the first space and through the windscreen sees a first space that can be experienced physically. Via the head-up display, a second space is simultaneously projected before his eyes as a mental concept of space. These spaces, when overlaid and integrated into each other, represent something like a "both/and" instead of an "either/or" through this hybridity, mobility and simultaneity. Such a complex understanding of space opens up new spaces.

This definitely appears to apply to the "augmented reality" navigation systems. In this case, a spatial image of absolute clarity, linearity and good organization is offered up to the possibly of still partially "jumbled" impressions on the windscreen projection area. In AR navigation systems, the windscreen itself has become a display for driving data and orientation systems that is consistently in line with military systems. The "enemy" of nature outside the windscreen is overlaid by its technified and reduced techno-aesthetic projection and therefore ultimately faded out.

\section{Connected navigation}

If as de Certeau (1988:169) argues, every reading modifies a text, then it can certainly be further deduced that every reading of a map changes the represented space laid down in writing. It can also be easily followed that a car navigation system will change the subjectively perceived space through its reception in the sense that a context, a structure and a generalization of this space takes place. In contrast, there is also a process whereby space changes the map. At the moment at which I drive through and traverse real space, I encumber it with subjective impressions and meanings that are not depicted on the map - thereby, the relationship to the map also changes. Even so, there is a spatial meaning that is prescribed by the map.

The advertisement for the "first virtual travel guide to the world" (iPublish, 2006b, own translation), the Merian scout Navigator is aimed at combating the loss of individual travel created by car navigation systems and the classical travel guides that led to a standardization of the tourist gaze (Urry, 1990): 


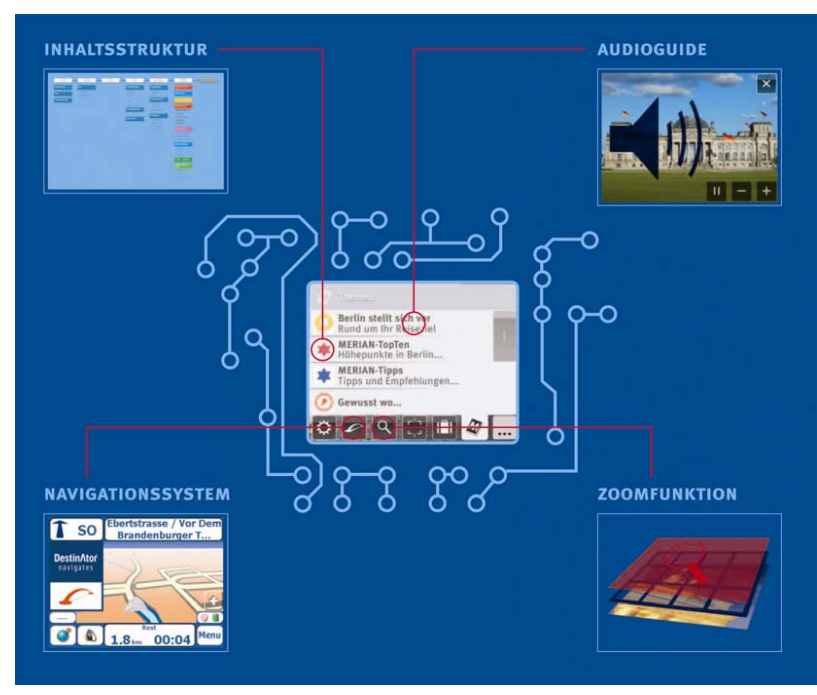

Fig. 7. Merian scout Navigator 2006. Figure caption: "Capacity for integration: The navigation software Destinator 6 is linked with digital travel guide programs, the contents of which stimulate, inform and entertain audiovisually. This is the technical basis for dream trips" (iPublish, 2006a:12, own translation).

"Navigation technology has made travel routine. We will make it a unique experience using the same technology! [...] Each trip is an individual story that should not be told, but experienced. The virtual travel guide is aimed at sustainably increasing the strength and diversity of these experiences. It opens up new spaces for experiences that far exceed the possibilities of representation offered by the usual tourist guides. With this, they smooth the path for a modern way of travel - Travel Scouting" (iPublish, 2006b:6f., own translation).

The approaches sketched out here for a subjective, strategic "undermining" of a cartographic trope (Crang, 1998:62ff.) should not, however, obscure the fact that this use of maps, the social practice of spatial reading, is no more capable of undermining the ideological-discursive function of the map. On the contrary, the Merian scout Navigator launched Fall 2006 - combines the contents of the classical travel guide (restaurant and hotel recommendations, places to go, information on culture, country and people etc.) with mobile navigation (see Fig. 7). If one drives past a place of interest, the system offers, for example, a "Drive By-Audio Guide", that gives a short audio presentation on the topic. In other words, the map's discursive function is completed by such a multimedia system. ${ }^{23}$

23 The artist project Trace presented in 1999 already combined GPS technology and sound samples to create a "memorial environmental sound installation". As the interactor (wearing open-headphones and a backpack containing a laptop-based GPS system) walked through the Yoho National Park in British Columbia different poems and musical or song compositions faded in and out according to location.

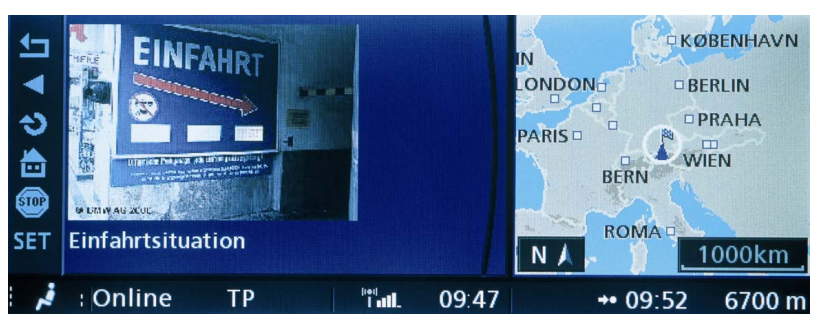

Fig. 8. BMW ConnectedDrive: The mobility service Park Info 2004.

The system provider iPublish, a daughter company of the German Ganske Publishing Group, can thereby not only utilize the interactive contents of the travel magazine Merian, but also the gourmet magazine Der Feinschmecker, the city magazine Prinz or the audio books published by the Hoffmann \& Campe publishing house. While driving through the Uckermark - the home of the German Chancellor Angela Merkel - it will be possible to listen to her biography Mein Weg or to simply let yourself be navigated to the closest party. This is where the convergence of cartography and media applications is particularly evident.

This convergence was already developed through the "first hypermedia program" (Manovich, 2001:259), the Aspen Movie Map, that made available panoramic camera experiments, thousands of still frames and audio in addition to basic travel footage (Naimark, 1997). Furthermore, "the Movie Map is a comprehensive alternative to both conventional maps and travelogues. [...] The experience is one of direct immersion in vicarious travel: a visit without being there" (Bolt, 1984:72f.).

The Aspen Movie Map combined the overview representation of a map with the self-guided experience of a city that simultaneously promised an immersion experience. Such simultaneous views, called "split-screen mode", are now offered only by the top-class car navigation systems. For example, the $B M W$ driving assistant systems Night Vision and ConnectedDrive show pictures taken by a heat-sensitive camera or real-life images on weather conditions, hotels, restaurants, parking garages on one side and cartographic information on the other side (see Fig. 8).

Given the new navigation systems, Manovich's comment that after the Aspen Movie Map "the idea of constructing a large-scale virtual space from photographs or a video of a real space was never tried out systematically again, although it opens up unique aesthetic possibilities not available with 3-D computer graphics" (Manovich, 2001:260) must be contradicted. The future of mobile navigation lies in the "augmented map": the hybrid representation of cartographic, real and virtual image information, whether on a head-up or a conventional display.

Different representations on different scales can also be looked at in parallel on the split-screen of the photorealistic Siemens-VDO navigation appliance (see Fig. 9). But 


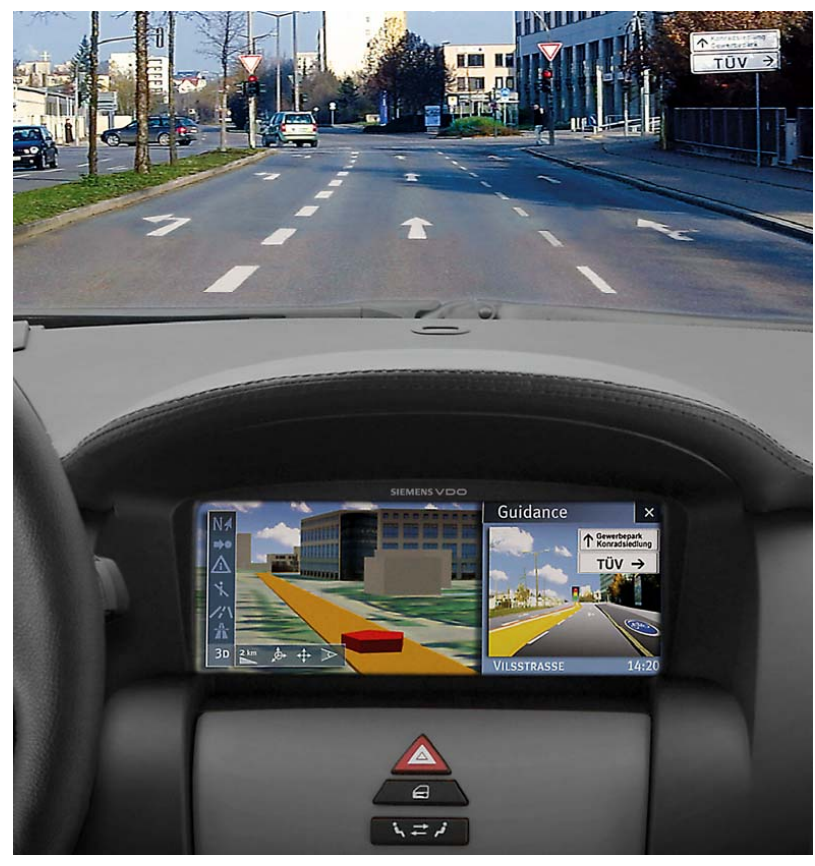

Fig. 9. Photorealistic three-dimensional map display from Siemens-VDO 2005.

furthermore, this system "is the first to compose the digital image from three maps at one time" (Siemens VDO Automotive, 2005). The user can switch between a conventional topographic map, the bird's-eye-view or a three-dimensional representation. However, Siemens-VDO was not the originator of this "trinity". Once again the Aspen Movie Map contained a mixture of map and video images as well as computer generated animations a quarter century before (Lippman, 1980:37ff.).

Nevertheless, today's generation of navigation devices are the first to be connected to real-time information. In contrast to prior generations of navigation systems, the orientation points on the Siemens-VDO are not isolated on the map, but are fully linked with the entire system and databases of other available information suppliers. It is therefore possible to obtain tourist information on important buildings, find out opening times and address data, make telephone connections or an internet linkage to the destination.

Temporal information in addition to spatial information is becoming increasingly important in the new navigation systems, with features such as real time gridlock reports aided by highway sensors (TMC Pro) or guidance to the nearest open drugstore - for example, possible with $B M W$ ConnectedDrive. "Spaces become places as they become 'time thickened'" (Crang, 1998:103).

Even if one believes that route guidance can be re-invented with "connected navigation" (ABI Research, 2006) and "travel scouting", it should be remembered that applications for matching address fields to coordinates, for showing tourist attractions and local businesses, for enhanced Yellow Pages as well as aids to marketing, field asset management and travel itinerary functions were already integrated into car navigation systems of the mid 1980's, such as ETAK Navigator and Philips CARIN (Zavoli and Honey, 1986:362; Thoone et al., 1987:2; Parviainen et al., 1988:193).

Overall, navigation systems seem to have more in common with travel photography than with the original use of GPS: the accurate targeting of ballistic missiles. It is therefore no surprise that the past and the future is destined to the fusion of travel guides and navigation systems.

\section{Positioning of the subject}

Even if there is a definition of space, as provided through the text and the ideology of the map, GPS also opens up a new possibility for subjective cartography. When space is read by the subjects themselves, it changes into a place with a different meaning, a place that refers to the subjects and to which the subjects themselves refer. The space of the Other (the cartographer's, the navigation system's) is transformed into one's own space (of perception, memories, expectation).

To date, however, there is little possibility for car navigation systems to record track logs, despite the fact that this function was already available in the Aspen Movie Map. The tracking of the personal is currently generally particular to artists' practice, known as "GPS Art". 24

According to Jody Berland (1996:125), the dream of traveling or the creation of travel records meet up with the passion for precise measurements in satellite imaging (and mapping). GPS not only registers the positional coordinates, but also records the high points, notable characteristics and special happenings on a trip - those personal experiences that are not entered onto conventional maps. For example, the three dimensional navigation system developed by Siemens-VDO is far less geared toward realistic perception of the surroundings, but more aimed at visualization of landscape and altitudinal profiles, to facilitate the planning and locating of off-road routes for drivers of cross-country vehicles.

However, and crucially, it should be remembered that the GPS receiver does not capture an objective representation, any more than does travel photography, but creates a visual display that can activate memories of subjective perspectives, perceptions linked to particular locations. Although the GPS representation of a trip consists only of a series of lines and points (of interest) and the self appears as a set of trajectories, it is principally the movements of the body that transforms the map from an omniscient territorial record to an individualistic medium of expression. So the tracking of

\footnotetext{
${ }^{24}$ For example, Masaki Fujihata is investigating the course of the border in the Alsace in his project Field-Works@alsace with the aid of a GPS receiver and visualizes movement in his field work as "postcards" (Hofmann, 2004).
} 
the personal turns the cartographic discourse into embodied practice (Rose, 1993:7). ${ }^{25}$

In order to permit car users to find their way through this maze of information, the positioning of a subject acquires a whole new meaning through technical niceties such as "dual-view car navigation displays". Thanks to the two-way viewing-angle LCDs developed by Sharp, passengers can enjoy films uninterrupted, while the chauffeur drives them through cities and countryside using the navigation system. The new seven inch screen type can simultaneously show different image information depending on the viewing angle. ${ }^{26}$ The speed of the information society therefore not only requires new theories on the visual, but also prompts new forms of subjectivity. Like the shifts in perspective that have marked the great ages of Western civilization, what Virilio (1997:24) calls the "trajective" state, a speedy state oscillating between the subjective and objective that maps movement from here to there, is a dynamic kind of "fractal subjectivity" (Haraway, 1991:193).

Even though his necrology for geography (Virilio, 1997:65) may appear somewhat premature, it is a lasting legacy of Virilio's dromological perspective, that locations and signs of the digital break in media history were discovered (Tholen, 2002:110). His "trajectography" (Virilio, 1997:129) questions the prevailing discourses in cartography. It should be borne in mind, that the construction of linear movements and spatial grids reduces not only the complexity of spatial practice, it also fades out possibilities for historical change. The navigation system's map has the potential to remove this reduction, as it visualizes self-generated movements, one's own trip in time and space, and a trajective position. Navigation systems can therefore help geography to be "the eye and the light for history" (Buci-Glucksmann, 1997:67, own translation) through GPS travel memories.

\section{Final position}

Maps are excellent material for the assistance, clarification and representation of augmented space, as already demonstrated by the Media Room. This is because our culture has been familiar with the dictum of overlaying with maps for centuries. During map reading there is a constant superpositioning of the map onto the physical space or real landscape (and in reverse). It is exactly this process that is taken on by visualization in augmented space.

\footnotetext{
25 Kant's transcendental philosophy (1781/2003) already points out that "Medialität" (the properties and forces generated by a medium), space and physicality are inseparably connected to each other. For the connection between body, medium and space, see also Doetsch, 2004.

26 The first driver assistance system with dual-view display was built into a Opel Vectra station wagon for testing purposes in 2005 (General Motors Europe, 2005).
}

The dynamic representation of location in navigation systems could therefore lead to a cross-disciplinary understanding of geography as a cognitive system in the widest sense of the phrase, which deals with the connections between subject and location. This not only re-evaluates the discursive positioning of the subject, but also integrates view points, difference strategies, contextualizations in space and time, and intelligible articulations (Rogoff, 1996:72).

For the purposes of further research, this perceptional geography, that incorporates entire media systems into topographic frameworks, and the convergence in cartographic, media and communication technologies, will require that car navigation systems are released from their primary functional context and considered within the greater context of geomedia, i.e. geobrowsers such as Google Earth, locative media, GPS-, WLAN- or RFID-systems.

In essence, navigation systems reflect the conditions on which orders are based as a counter-site for spatial orders. They visualize the heterotopia of driving cars, the capacity to connect to other positions (emplacements) and therefore, with positioning that contradicts the order of placements, they have the potential to neutralize them or reverse the entirety of their structural relationships. Even if they no longer use cartographic symbols, the possibility for dis-orientation inherent in navigation systems remains an original geographic characteristic. Such de-mapping is not unlikely, as cars have access to an interface via the new generation of navigation systems, that permits hackers not only to display data garbage on navigation displays, but also to access the on-board electronics and to cause accidents (Grell, 2005:81).

The possibility of dysfunction and disturbance created by "connected navigation", in combination with the impetus provided by Foucault's, Soja's and Virilio's theories on space, bestow categorical autonomy upon the navigation system medium. This makes it all the more plausible, at least from a media theoretical perspective, to describe the area of phenomena outlined here with the more comprehensive term, geomedia. With reference to trajectography, the indexing and ubiquitous geomedium display proves that this makes sense. While "in Virilio's writing, the screen serves as the locus of lost dimensions of space" (Friedberg, 2004:183), nowadays the display is the locus of recovered dimensions of space. ${ }^{27}$

Acknowledgements. I am very grateful to D. Bissell, S. Günzel, $\mathrm{S}$. Werkmeister and one anonymous referee for their generous and helpful comments on a previous version of this essay. Finally, I would like to thank the editors, A. Schlottmann and J. Miggelbrink, for their thorough review and providing unfailing help as well as for organizing the conference "Visualisierung des Raumes I -

\footnotetext{
27 Not cinema screens or cathode ray tubes, but liquid crystal displays are now the dominating screen medium (Thielmann, 2006). Virilio therefore displayed much foresight in not theorizing on the technological differences between film, television and computer screens.
} 
Produzieren, Profilieren, Präsentieren" in which this paper was originally presented.

Edited by: A. Schlottmann

\section{References}

ABI Research (Ed.): Wireless Connectivity the Future for Portable Navigation Devices, Press Release, New York, October 23, 2006.

Benjamin, W.: Die Aufgabe des Übersetzers (1921), in: Benjamin, W.: Gesammelte Schriften, edited by: Tiedemann, R., Suhrkamp, Frankfurt/M., Bd. IV. 1, pp. 9-21, 1980

Berland, J.: Mapping Space: Imaging Technologies and the Planetary Body, in: Technoscience and Cyberculture, edited by: Aronowitz, S. and Martinsons, B., Routledge, New York, pp. 123-138, 1996.

Bolt, R. A.: Spatial Data Management, Interim Report, MIT Architecture Machine Group, Cambridge, MA, November, 1977.

Bolt, R. A.: Spatial Data Management, DARPA Report, MIT Architecture Machine Group, Cambridge, MA, March, 1979.

Bolt, R. A.: The Human Interface: Where People and Computers Meet, Lifetime Learning Publications, Belmont, CA, 1984.

Brand, S.: The Media Lab, Inventing the Future at MIT, Penguin Books, London, 1988.

Buci-Glucksmann, C.: Der kartographische Blick der Kunst, Merve, Berlin, 1997. [Original: Buci-Glucksmann, C.: L'CEil Cartographique de L'Art, Galilée, Paris, 1996.]

Ceruzzi, P. E.: A History of Modern Computing, MIT Press, Cambridge, MA, 2nd edn., 2003.

Crang, M.: Cultural Geography. Routledge, London, 1998.

Crisp, J.: In-Car High Tech, Newsweek, 106, 43, Special Advertising Section, 1985.

De Kerckhove, D.: The Architecture of Intelligence, Birkhäuser, Basel, 2001.

Doetsch, H.: Intervall. Überlegungen zu einer Theorie von Räumlichkeit und Medialität, in: Von Pilgerwegen, Schriftspuren und Blickpunkten. Raumpraktiken in medienhistorischer Perspektive, edited by: Dünne, J., Doetsch, H., and Lüdeke, R., Königshausen \& Neumann, Würzburg, pp. 23-56, 2004.

Donohoe, D. and Leroux, P.: In-Car Navigation, GEO:connection International, 4, 8, 48-49, 2005.

Downs, R. M. and Stea, D.: Kognitive Karten. Die Welt in unseren Köpfen. Harper \& Row, New York, 1982. [Original: Downs, R. M. and Stea, D.: Maps in Minds: Reflections on Cognitive Mapping. Harper \& Row, New York, 1977.]

Fernhout, H. C.: The CARIN Car Information and Navigation System and the Extension to Carminat, in: 6th International Conference on Automotive Electronics: 12-15 October 1987, pp. 139-143, IEE, London, 1987.

Foucault, M.: Of Other Spaces, Diacritics, 16, 1, 22-27, 1986. [Original: Foucault, M.: Des espaces autres (1967), in: Foucault, M.: Dits et Écrits. 1954-1988. Tome IV, pp. 752-762. Gallimard, Paris, 1994.]

French, Robert L.: Historical Overview of Automobile Navigation Technology, IEEE Vehicular Technology Conference Proceedings, 36, 350-358, 1986.

Friedberg, A.: Virilio's Screen: The Work of Metaphor in the Age of Technological Convergence, Journal of Visual Culture, 3, 2,
183-193, 2004.

Gartner, G.: TeleKartographie, GeoBIT/GIS, 13, 4, 21-24, 2000.

Gartner, G.: "Mobile Internet" als Voraussetzung für die Telekartographie, in: Telekartographie und Location Based Services, edited by: Kelnhofer, F. and Lechthaler, M., Institut für Kartographie und Geo-Medientechnik, Wien, pp. 27-39, 2002.

General Motors Europe (Ed.): Opel Presents Innovations for Tomorrow's Mobility. Press Release, Glattbrugg/Rüsselsheim, 18 August 2005

Gibson, W.: Neuromancer, Ace Books, New York, 1984.

Grell, D.: Tacho-Tüfteln. Was tun gegen die Kilometerstandfälscher, C't, 78-81, 4 April 2005.

Haraway, D.: Simians, Cyborgs and Women, Routledge, New York, 1991.

Harley, J. B.: Maps, Knowledge, and Power, in: The Iconography of Landscape. Essays on the Symbolic Representation, Design and Use of Past Environments, edited by: Cosgrove, D. and Daniels, S., Cambridge University Press, Cambridge, pp. 277-312, 1988.

Harvey, D.: The Condition of Postmodernity: An Enquiry into the Origins of Cultural Change, Blackwell, Oxford, 1989.

Heidmann, F. and Hermann, F.: Benutzerzentrierte Visualisierung raumbezogener Informationen für ultraportable mobile Systeme, in: Visualisierung und Erschließung von Geodaten. Kartographische Schriften, Bd. 7, edited by: Dodt, J. and Rase, W. D., Kirschbaum, Bonn, pp. 121-131, 2003.

Hipfl, B.: Mediale Identitätsräume. Skizzen zu einem "spatial turn" in der Medien- und Kommunikationswissenschaft, in: Identitätsräume: Nation, Körper und Geschlecht in den Medien, edited by: Hipfl, B., Klaus E., and Scheer U., Transcript, Bielefeld, pp. 16-50, 2004.

Hofmann, F.: Über Raum. Masaki Fujihata: Field-Works@alsace, in: Raum - Dynamik. Beiträge zu einer Praxis des Raums, edited by: Hofmann, F., Transcript, Bielefeld, pp. 265-268, 2004.

Honda (Ed.): The Car Navigation System (1981), Gyro Research: The World's First Automotive Navigation System, www.world. honda.com/history/challenge/1981 navigationsystem/index.html (download: 12-30-2006), n.d.

Hutchins, E.: Material Anchors for Conceptual Blends, Journal of Pragmatics, 37, 1555-1577, 2005.

iPublish (Ed.): Merian scout Navigator: Innovation durch Transformation. Booklet, Ganske Interactive Publishing, München, 2006a.

iPublish (Ed.): Ziele, Wege, Attraktionen. Das kleine Zauberbuch der virtuellen Reiseführung. Booklet, Ganske Interactive Publishing, München, 2006b.

Kant, I.: Kritik der reinen Vernunft, Fourier, Stuttgart, 2003 [Original: Riga, 1781.]

Lippman, A.: Movie-Maps: An Application of the Optical Videodisc to Computer Graphics, Computer Graphics, 14, 3, 32-42, 1980

Lopau, W.: Die räumliche Orientierung von mobilen Displaygeräten, Kartographische Nachrichten, 53, 2, 64-67, 2003.

Manovich, L.: The Language of New Media, MIT Press, Cambridge, MA, 2001.

Mark, D. M., Gould, M. D., and McGranaghan, M.: Computerized Navigation Assistance for Drivers, Professional Geographer, 39, 2, 215-220, 1987.

Matussek, P.: Computer als Gedächtnistheater, in: Metamorphosen: 
Gedächtnismedien im Computerzeitalter, edited by: Darsow, G. L., Frommann-Holzboog, Stuttgart, pp. 81-101, 2000.

McLuhan, M.: Understanding Media: The Extension of Man, McGraw-Hill, New York, 1964.

Miller, G. A.: Psychology and Information, American Documentation, 19, 3, 286-289, 1968.

Murray, C: IC Makers Roll Dice on 3-D Car Navigation, EE Times, www.eetimes.com, 15 November 2004.

Naimark, M.: 3D Moviemap and a 3D Panorama, SPIE Proceedings, 3012, 297-305, www.naimark.net/writing/spie97. html (download: 07-01-2006), 1997.

Naimark, M.: Aspen the Verb: Musings on Heritage and Virtuality, Presence. Teleoperators and Virtual Environments, 15, 3 [Special Issue: Virtual Heritage], 330-335, www.naimark.net/writing/ aspen.html (download: 12-30-2006), 2006.

Neisser, U.: Cognition and Reality. Principles and Implications of Cognitive Psychology, Freeman, San Francisco, 1976.

N.N.: Der Handy-Markt im Detail, TeleTraffic, 2, 1, 21, 2006.

Pammer, A. and Radoczky, V.: Multimediale Konzepte für mobile kartenbasierte Fußgängernavigationssysteme, in: Geoinformation mobil, edited by: Zipf; A. and Strobl, J., Wichmann, Heidelberg, pp. 117-126, 2002.

Pápay, G.: Kartografie, in: Bildwissenschaft, edited by: Sachs-Hombach, K., Suhrkamp, Frankfurt/M., pp. 281-295, 2005.

Parviainen, J. A., French, R. L., and Zwahlen, H. T.: Mobile Information Systems Impact Study. Ontario Ministry of Transportation, Downsview, ONT, www.itsdocs.fhwa.dot.gov/ /JPODOCS/REPTS_TE/84V01!.PDF (download: 07-01-2006), 1988.

Reichenbacher, T. and Meng, L.: Mobile Kartographie ein Annäherungsversuch an ein neues Forschungsthema, Kartographische Nachrichten, 53, 1, 4-5, 2003.

Rogoff, I.: Die Anderen der Anderen: Spectatorship und Differenz, in: Die Wiederkehr des Anderen. Interventionen 5. Museum für Gestaltung Zürich, edited by: Huber, J. and Müller, A. M., Stroemfeld, Basel and Frankfurt/M., pp. 63-82, 1996.

Rose, G.: Feminism and Geography. The Limits of Geographical Knowledge, University of Minnesota Press, Minneapolis, MN, 1993.

Rueb, T.: Traces: A Memorial Environmental Sound Installation, Banff Centre for Arts, Canada, www.terirueb.net/old_www/trace/ paper.html (download: 07-01-2006), 1999.

Sandbothe, M.: Pragmatische Medienphilosophie: Grundlegung einer neuen Disziplin im Zeitalter des Internet, Velbrück, Weilerswist, 2001.

Scharlach, H. and Müller J. C.: Multimediale thematische Kartographie auf Handheld PCs: Potentiale und Grenzen, in: Telekartographie \& Location Based Services, edited by: Kelnhofer, F. and Lechthaler, M., Institut für Kartographie und Geo-Medientechnik, Wien, pp. 87-98, 2002.

Schmaucks, D.: Standortdarstellungen - Varianten selbstbezüglicher Lokalisierung, in: Bildhandeln, edited by: Sachs-Hombach, K., Scriptum, Magdeburg, pp. 305-314, 2001.

Scholz, O. R.: Bild, Darstellung, Zeichen. Philosophische Theorien bildhafter Darstellung. Klostermann, Frankfurt/M., 2nd edn., 2004.
Shuldiner, H.: Here now: Computerized Navigator for your Car, Popular Science, 226, 6, 64-67, 1985.

Siemens VDO Automotive (Ed.): A New Dimension of Navigation: Photo-quality Three-dimensional Map Display from Siemens VDO, Press Release, Schwalbach/Shanghai, 6 December 2005.

Sommer, M.: Suchen und Finden. Lebensweltliche Formen, Suhrkamp, Frankfurt/M., 2002.

Soja, E.: Thirdspace: Expanding the Scope of the Geographical Imagination, in: Human Geography Today, edited by: Massey, D., Allen, J., and Sarre, P., Polity Press, Cambridge, pp. 260-278, 1999.

Sutherland, I. E.: The Ultimate Display, Proceedings of the IFIP Congress, 65, 2, 506-508, 1965.

Thielmann, T.: Statt einer Einleitung: Eine Mediengeschichte des Displays, in: Display I: Analog, edited by: Schröter, J. and Thielmann, T., Schüren, Marburg, pp. 13-30, 2006.

Thielmann, T.: Der ETAK Navigator: Tour de Latour durch die Mediengeschichte der Autonavigationssysteme, in: Bruno Latours Kollektive. Kontroversen zur Entgrenzung des Sozialen, edited by: Kneer, G., Schroer, M., and Schüttpelz, E., Suhrkamp, Frankfurt/M., in press, 2007.

Tholen, G. C.: Die Zäsur der Medien. Suhrkamp, Frankfurt/M., 2002.

Thoone, M. L. G., Driessen, L. M. H. E., Hermus, C. A. C. M., and van der Valk, K.: The Car Information and Navigation System CARIN and the Use of Compact Disc Interactive, SAE Technical Paper Series, 870139, 1-7, 1987.

Tolman, E.C.: Cognitive Maps in Rats and Men, Psychological Review, 55, 189-208, 1948.

Urry, J.: The Tourist Gaze. Leisure and Travel in Contemporary Societies, Sage Publications, London, 1990.

Virilio, P.: Fahrzeug, in: Aisthesis. Wahrnehmung heute oder Perspektiven einer anderen Ästhetik, edited by: Barck, K., Gente, P., Paris, H., and Richter S., Reclam, Leipzig, pp. 47-72, 1992. [Original: Virilio, P.: Véhiculaire, in: Nomades et Vagabonds, edited by: Berque, J., Virilio, P., Ziegler, J. et al., Union générale d'éditions, Paris, 1975.]

Virilio, P.: Open Sky, Verso, London, 1997.

Virilio, P.: Dromoscopy, or The Ecstasy of Enormities, Wide Angle, 20, 3, 11-22, 1998.

Virilio, P. and Lothringer, S.: Der reine Krieg, Merve, Berlin, 1984. [English: Virilio, P and Lothringer, S.: Pure War, Semiotext(e), New York, 1983.]

Wagner, F.: Navigationsgeräte können künftig sehen, Handelsblatt ePaper, www.handelsblatt.com, 30 January 2005.

Warnke, M: 'Et mundus, hoc est homo'. Von einer sehr alten, nun wieder virtuellen Weltkarte, Zeitschrift für Semiotik, 20, 1-2, 119-132, 1998.

Wunderlich, D.: Raumkonzepte. Zur Semantik der lokalen Präpositionen, in: Nach-Chomskysche Linguistik, edited by: Ballmer, T. T. and Posener, R., de Gruyter, Berlin and New York, pp. 340-351, 1985.

Zavoli, W. B. and Honey, S. K.: Map Matching Augmented Dead Reckoning, IEEE Vehicular Technology Conference Proceedings, 36, 359-362, 1986. 